\title{
Algorithmisation and Tokenisation of Law
}

Rafat Prabucki, Rafat Skibicki, Dariusz Szostek, Jakub Wyczik

Donda's Law:"What a small computer can do with a large program, a large computer can also do with a small program; hence the logical conclusion is that an infinitely large program can work alone, i.e. without any computer". - S. Lem, "From the memoirs of Ijon Tichy"

\section{Introduction}

Codes, after Legal Design, are the second most rapidly growing branch of legal engineering within LegalTech, which is a consequence of increasing the willingness to have the impact of law on society by transcribing regulations into code or, similarly, increasing the impact of arrangements between parties in commercial transactions. More than 22 years ago, at the end of the 20th century, Lawrence Lessig in his bestselling monograph "Code and Other Laws of Cyberspace" ${ }^{1}$ proposed to link law with algorithmic code. Since law regulates the rights and obligations of subjects, and algorithmic code is the regulator of cyberspace, it is natural to link them. Code is law. A year earlier, J. Reidenberg ${ }^{2}$ had proposed that "Lex Electronica" should regulate itself through "architecture standards", e.g. through properly configured codes as the legal regulator of cyberspace. Two decades ago this concept was considered by many to be futuristic, or at most, futurological. Today we are witnessing its realization and this phenomenon can be observed not only in private law in smart contracts, but also in increasingly daring government projects, such as the ones relating to the legislative process or even the incorporation of law into codes. By way of examples only, here can be mentioned the proposal of

1 Lawrence Lessig, Code and Other Laws of Cyberspace (1st edn, Basic Books 1999).

2 Joel Reidenberg, 'Lex Informatica: The formulation of information policy rules through technology' (1998) 76 Texas Law Review 553. 
G. Wood ${ }^{3}$ to regulate the law on cryptocurrencies in algorithmic codes as well as the concepts of A. Wright \& P. De Filippi ${ }^{4}$ and additionally also the one which relates to D. Szostek ' ${ }^{5}$ proposal to regulate AI codes with algorithmic codes, at least by using RegTech.

Undoubtedly, for several decades now, there has been an increasing integration of law and algorithmic codes at various levels starting from the regulation of algorithms, through law, to the incorporation of law (e.g. contracts) into codes. This integration will continue to deepen more and more. In this chapter some aspects and problems related to the use of algorithmic codes in law will be pointed out.

\section{Code, Algorithms, Algorithmic Technology}

Operating with the terms - code and algorithm - is difficult, mainly due to their interdisciplinary nature. However, it should be emphasised that the term "algorithm" is not reserved exclusively for an academic discipline such as computer science and the IT sector. The term has a universal meaning. A uniform and universally accepted definition of an algorithm has not been developed in the world. However, many researchers from different fields are taking attempts to solve this problem ${ }^{6}$. The main trouble arises from the fact that there is no single type of algorithm. Most agree, however, that the general concept of an algorithm involves general processes for producing some "output" data (ang. output) from an "input" data (ang. input), through the use of various symbols with a finite set of rules. All algorithms must be specified in a formal language with a set of well-defined rules. However, this still does not solve the problems of definition. Nevertheless, in American jurisprudence, algorithms were defined rather laconically in Gottschalk v. Benson case law as ${ }^{7} "(. .$.$) a procedure for$ solving a certain mathematical problem". International doctrine, however,

3 Gavin Wood, 'Ethereum: A secure decentralised generalised transaction ledger' GAVWOOD.COM <https://gavwood.com/paper.pdf $>$ accessed 11 December 2020;

4 Aaron Wright and Primavera De Filippi, 'Decentralized blockchain technology and the rise of Lex Cryptographia' (2015) <https://ssrn.com/abstract=2580664> accessed 11 December 2020.

5 Dariusz Szostek, 'Sztuczna Inteligencja a kody' in Luigi Lai and Marek Świerczyński (eds), Prawo sztucznej inteligencji (C. H. Beck 2020) 15.

6 Samuel R. Buss, Alexander S. Kechris, A. Pillay and Richard A. Shore, 'The Prospects for Mathematical Logic in the Twenty-first Century' (2001) 7 Bulletin of Symbolic Logic 169.

7 Gottschalk v Benson (1972) 409 U.S. 63. 
tries to perceive the issue of algorithms more broadly, presenting them as rules or instructions, the execution of which allows to solve a certain problem. In a nutshell, an algorithm is a synonym for a procedure that aims at solving a specific problem ${ }^{8}$. In this approach, therefore, a type of algorithm is both a mathematical formula and an instruction to assemble furniture.

As it has already been mentioned, algorithms may take various forms, including different implementations. Nowadays they are, among others, the basis of computer science and computer programs. The starting point for consideration of the legal status of computer programs in the international doctrine was the assumption that algorithms are written as programs by means of codes 9 . However, it is impossible to find an indisputable limit of the scope of these concepts on the grounds of legal logic. The first thing that should be stressed, therefore, is that there is no generally accepted meaning of the word. This is not an exceptional situation, as the same is the case with technology and with many other words from the sphere of exact sciences. Moreover, computer programs do not have a uniform definition. During the preparatory work on the WIPO Copyright Treaty $(\mathrm{WCT})^{10}$, it was agreed that a computer program should be understood as "a set of instructions which, when placed on a machine-readable medium, will enable to cause a machine with information processing capabilities to indicate, perform or achieve a specific function, task or result"11. However, this definition was not reflected in the final text of the act. Similarly, in the case of European Directive 2009/24/EC on the legal protection of computer programs ${ }^{12}$ it was decided not to include a definition of this phrase, in order to avoid

8 cf Rob Kitchin, 'Thinking critically about and researching algorithms' (2017) 20:1 Information, Communication \& Society 14; See Barfield Woodrow and Pagallo Ugo, Advanced Introduction to Law and Artificial Intelligence, Cheltenham (Edward Elgar Publishing 2020).

9 See Idelle R. Abrams, 'Statutory Protection of the Algorithm in a Computer Program: A Comparison of the Copyright and patent laws' (1989) 9:2 Computer Law Journal.

10 World Intellectual Property Organization treaty [1996].

11 WIPO document states: "set of instructions capable, when incorporated in a machine-readable medium, of causing a machine having information-processing capabilities to indicate, perform or achieve a particular function, task or result", (WIPO) $<$ www.wipo.int/edocs/mdocs/copyright/en/wipo_ip_cm_07/wipo_ip_cm_07_ww w_82573.doc $>$ accessed 11 December 2020.

12 Directive 2009/24/EC of the European Parliament and of the Council of 23 April 2009 on the legal protection of computer programs (Codified version) [2009] OJ L11/16. 
its rapid obsolescence due to technological progress ${ }^{13}$, and therefore, it was decided to be restricted to stating only that "the role of software is to interact and function together with other components of a computer system and with users, [and] in order to achieve this, it is required that there be logical and, where appropriate, physical interconnection and interaction so as to permit all elements of software and hardware to function with other software, hardware and users in all the forms of operation for which they are intended" ${ }^{14}$, further stating that its interfaces ${ }^{15}$ are part of it, which ensure interoperability ${ }^{16}$. Consequently, computer programmes are recognised by source and result codes. However, there is no clear definition at all of what programming code actually is. It is, however, impossible not to agree that it is simply a kind of written text, constituting a system of signs ${ }^{17}$, which is comprehensible for computers. Putting the abovementioned together with the notion of an algorithm, a computer program is essentially a type of algorithm, which is implementable as a text containing sets of commands to be executed by a machine. Programming code is in fact an algorithm that makes it possible to achieve a specific result. Although the legal

13 Which, it seems, was not necessarily the case. Modern computer programs in their nature have not changed that much from their original versions. The definition set out above still seems to touch the essence. This is confirmed by the still unchanged definition of computer programs in U.S. law, which does not hinder the thriving high-tech industry (17 U.S.C. \$101). See also African Regional Intellectual Property Organization, 'ARIPO Model Law on Copyright and Related Rights' (ARIPO, July 2019) <https://www.aripo.org/wp-content/uploads/2019/10/ARIPO-Model-Law-on -Copyright-and-Related-Rights.pdf $>$ accessed 11 December 202010.

14 Recital 10 of Directive 2009/24/EC.

15 However, as is clear from the CJ case law, a graphical user interface does not allow for the reproduction of a computer program and therefore does not constitute a form of expression of a computer program within the meaning of the Software Directive and thus cannot benefit from the special protection granted thereunder. See Case 393/09 Bezpečnostni softwarová asociace - Svaz softwarové ochrany v Ministerstvu kultury [2010] ECLI:EU:C:2010:816, paras 28-42.

16 As defined in Directive 2009/24/EC, being the functional, interconnection and interaction of software, enabling it to function with other software, hardware and users according to its intended use.

17 According to Wikipedia: "code is a system of rules to convert information-such as a letter, word, sound, image, or gesture - into another form, sometimes shortened or secret, for communication through a communication channel or storage in a storage medium" Wikipedia, 'Code' <https://en.wikipedia.org/wiki/Code> accessed 11 December 2020 . 
status of programming code raises many doubts, particularly as a result the controversial CJEU case law affecting the interpretation of European law ${ }^{18}$.

In the last decade, however, algorithms as such have become of more intense interest to representatives of many scientific fields as a result of the development of AI, becoming its main core. The concept of $\mathrm{AI}$ is as undefined as the algorithm itself. For the purpose of scientific discussion, without having to delve into the definitional problem there can be encountered an approach of defining AI and algorithms collectively as algorithmic technology (ang. Algorithmic-based technology) ${ }^{19}$. However, attempts are being made in international doctrine to structure the systematics of artificial intelligence. Such a proposal was presented by $B$. Woodrow i $P$. Ugo (Figure 1).

Figure 1. Types and distinctions of artificial intelligence in international legal doctrine

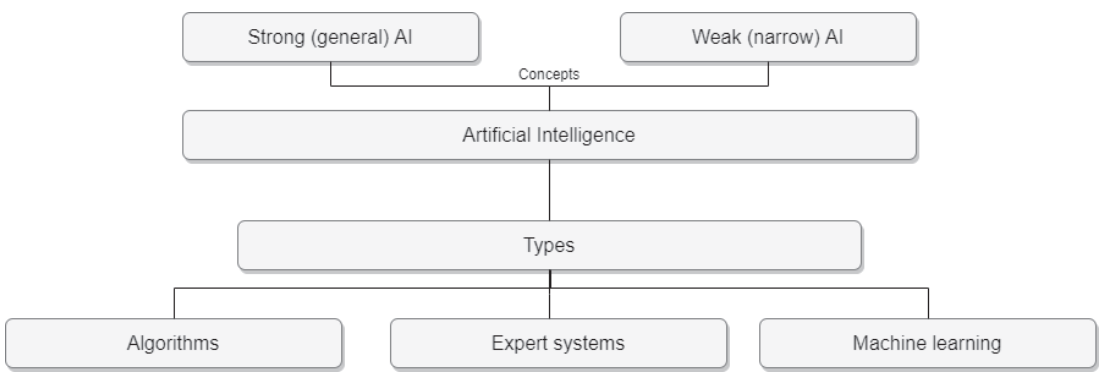

Source: Own elaboration based on W. Barfield, U. Pagallo, Law and Artificial Intelligence, Cheltenham-Northhampton 2020, pp. 19-23.

An independent group of experts from the European Commission also came up with a definition, proposing that AI systems are software (and possibly hardware) developed by humans that operate in the physical or digital domain in pursuit of goals, perceiving their environment by collecting and interpreting data, relying on knowledge or information derived from this data, and taking the best steps to accomplish the tasks

18 See for example Case 128/11 UsedSoft GmbH v Oracle International Corp [2012] ECLI:EU:C:2012:407.

19 See Marta C. Gamito and Martin Ebers, 'Algorithmic Governance and Governance of Algorithms: An Introduction' in Martin Ebers and Marta C. Gamito (eds), Algorithmic Governance and Governance of Algorithms: Legal and Ethical Challenges (Springer 2021). 
assigned to them ${ }^{20}$. This definition is therefore primarily based on viewing AI through the prism of a characteristic type of algorithms. AI systems can use well-known mathematical concepts for their operation, implementing them into modern technological solutions, as well as they can simultaneously adapt to the changing environment on the basis of previously made decisions. Intelligent algorithms thus differ from standard algorithms implemented in computer programs. However, such a broad definition of term leads at the same time to the inclusion in its scope of many different solutions, ranging from roboadvisors (or chatbots), interactive translators, facial or voice recognition systems, virtual opponents in computer games, to automated financial market management systems or autonomous androids. It seems obvious that this approach in defining will be insufficient. In fact, it is impossible to equate a translation system with an android. Hence, some representatives of the doctrine postulate that there is no need for a uniform definition of $\mathrm{AI}^{21}$. Thus, in order for the law to be effective, it is necessary to focus on individual solutions using AI instead of trying to complexly regulate all its types which appear to be doomed to failure from the outset. The general role of algorithms and AI in what we understand as LegalTech is related to the direction in which algorithmic techniques are to be used in legal practice. The theory of the path that depicts these directions was presented as early as 1897 by Oliver Wendell Holmes Junior ${ }^{22}$ :

1) direction one: it aims at creating useful solutions to minimise the risk of litigation between the parties;

2) second direction: it involves carrying out argumentation before the dispute resolution body.

20 High-Level Expert Group on Artificial Intelligence, established by the European Commission: „Artificial intelligence (AI) systems are software (and possibly also hardware) systems designed by humans, that given a complex goal, act in the physical or digital dimension by perceiving their environment through data acquisition, interpreting the collected structured or unstructured data, reasoning on the knowledge, or processing the information, derived from this data and deciding the best action(s) to take to achieve the given goal”, High-Level Expert Group on Artificial Intelligence, 'A definition of Al.: Main capabilities and scientific disciplines' 6 (European Commission, April 2019) <https://ec.europa.eu/news room/dae/document.cfm?doc_id=56341> accessed 11 December 2020.

21 Martin Ebers, 'Regulating $\overline{\mathrm{AI}}$ and Robotics: Ethical and Legal Challenges' in Martin Ebers and Susana Navas (eds), Algorithms and Law (Cambridge University Press 2020) 42.

22 Oliver W. Holmes, 'The Path of the Law' (1897) 457 Harvard Law Review. 
In the first direction, in addition to supporting the lawyer in his work, there will be encountered a tendency to write down the court decisions between the parties in such a way as to make them readable to a machine which will automate certain transactions between the parties. The desired effect is to reduce the risk of litigation and thus to make the solution highly usable (a smart contract is an example ). According to David Howarth it is precisely the right direction for law to be perceived as engineering ${ }^{23}$. The second direction is related to the implementation of solutions to both help the legal practitioner in the preparation of legal argumentation as well as can create tools for the dispute resolution body, indicating which arguments are properly constructed and supported by relevant evidence ${ }^{24}$.

However, from a LegalTech perspective, it is freedom of contract and legal engineering skills in creating contracts that should be thoroughly discussed. Where there is freedom in the legal system, there is equally the need to build trust. This can be constructed between the parties through contractual provisions. Historically, landmark events requiring trust between parties (e.g. the establishment of the American stock exchange), required a contract to be written in natural language and were local initiatives. Thanks to the development of new technologies, as well as the global nature of the parties' relationship and also due to the need for a high level of trust, certain relationships are regulated by means of a computer program, and a computer program is de facto a code ${ }^{25}$.

\section{Law as a Code}

As indicated at the beginning, technological developments have led to the concept of transcribing law into codes. The conceptual scope of legal engineering has also changed. The early conception of the cited view formulated by Howarth implied that law perceived as engineering is supposed to create useful solutions and, in the context of the work of a legal practitioner, it is expected to involve contracts ${ }^{26}$. Nowadays, the conceptual scope has evolved. There is no doubt that this is due to the transition

23 David Howarth, Law As Engineering: Thinking about What Lawyers Do (Edward Elgar Publishing 2014).

24 See Douglas Walton, Argumentation Methods for Artificial Intelligence in Law (Springer 2005) 5-8.

25 Kevin Werbach, The Blockchain and the new architecture of trust (MIT Press 2018) 1-7.

26 Howarth (n 23) 51-152. 
from the level of consideration of lex informatica to lex cryptographia in international legal doctrine. A modest approach to this process can be seen in the work of G. Wood, who observed that it was the development of cryptography that would result in the realisation of law as a code. In his view, crypto-law is characterised by the fact that it is possible to write certain rules known from traditional law in a strongly secure space, thanks to advanced cryptography (hence the term crypto-) of the space. According to Wood, the moment of real implementation of crypto-law is related to the development of blockchain technology. As an example, the author cites Ethereum ${ }^{27}$. The concept of crypto-law practically refers to cryptocurrencies, but the basis of this approach is related to the work of Mark S. Miller, in which the process of moving away from law to its new approach was presented and where the impracticality of law in the era of developing new technologies was recognised. Along with the diminishing importance of law in the aspect of building trust in the relations of global society, the role of computer security techniques - including cryptography - is increasing. The intersection of decline and growth is the point at which law in the traditional model will stop existing ${ }^{28}$. Although this theoretical approach sounds evolutionary, from the perspective of many years of law formation it looks like an abrupt change, especially as the basic assumptions of traditionally understood law are subject to ongoing changes ${ }^{29}$.

Both Ethereum and Bitcoin are concepts that use advanced cryptography to build a trusted place in cyberspace where code-based solutions can be created. According to the Lex Cryptographia approach, they can be challenging for certain legal systems, due to the fact that the concepts used are created independently of the law factor assigned to a certain territory (e.g. DAO - equivalent to a certain type of company contract, foundation, etc., but with high anonymity of the partners or members of the organisation and with its own management rule $)^{30}$.

The quintessential point is that both cryptocurrency and Lex Cryptographia is a smart contract written in a block (as in Ethereum), or otherwise named place for transaction data in some register, code. This

27 cf Wood (n 3); See Wright and De Filippi (n 4).

28 Mark S. Miller, 'The Future of Law' CAPLET.COM (August 1997) <www.caplet.c $\mathrm{om} /$ security/futurelaw $>$ accessed 16 March 2021.

29 Dariusz Szostek, 'Consequences of applying new technologies to sources of law' in García G. Javier, Alzina L. Álvaro and Martín R. Gabriel (eds), El derecho público y privado ante las nuevas tecnologías (Dykinson 2020).

30 See Wright and De Filippi (n 4). 
code implements certain automated decisions (ADM, from automated decision making) regarding transactions. In certain legal systems, it may be a contract in its own right that complies with certain civil laws, or it may be an element of such a contract, i.e. its structure may fall within contractual regulations in certain provisions. The creator of this concept was Nick Szabo, and a smart contract in its current sense is associated with blockchain solutions. Additionally, D. Szostek, following the definitional scope indicated by the author, notes that bitcoin should also be considered as a certain zero form of smart contract ${ }^{31}$.

\section{Figure 2. Graphical representation of the Ricardian contract concept}

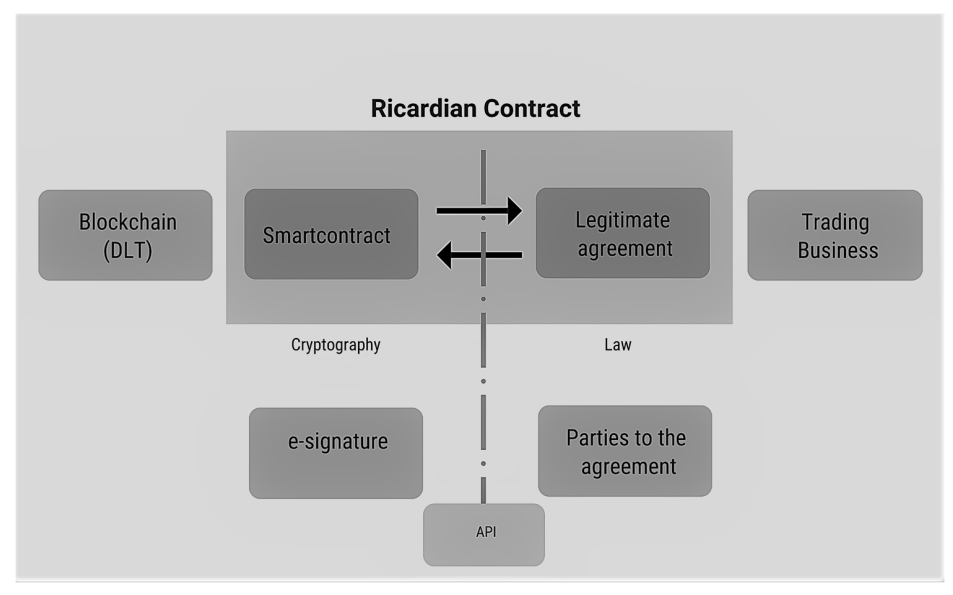

Source: Own elaboration.

However, fixing code in the form of a smart contract requires specialised, non-legal knowledge. Ethereum-based smart contracts typically use the Solidity programming language, which is a type of high-level object-oriented language developed on top of $\mathrm{C}++$, Python and JavaScript ${ }^{32}$. Provisions for the parties written in this kind of artificial language will not be understandable to, for example, a court in the event of a litigation. On the other hand, it does not seem possible for this type of agreement to go completely beyond the current legal regulations and thus remain in a kind of magic

31 Dariusz Szostek, Blockchain and the law (1st edn, Nomos 2019) 111.

32 Solidity Documentation: <https://docs.soliditylang.org/en/v0.8.0/> accessed 17 January 2021. 
circle $^{33}$. Therefore, for effective management of such contracts, close cooperation between the programmer and the lawyer will be necessary. The golden mean in this matter comes from the Ricardian approach and serves to balance things out. The so-called Ricardian contract assumes that, on the one hand, a provision will be drawn up for the parties in the form of a certain natural language using a specialised legal language, but an integral part of the contract will be the transfer of part or the writing of part of the provisions in a programming language ${ }^{34}$. If this becomes applicable in the current reality, advanced cryptographic techniques (electronic signature, blockchain) will enable the operation of smart contracts, and moreover, a contract drawn up in a legal manner will guarantee the existence of provisions in artificial languages in business dealings regulated in a traditional manner, i.e. by law. In such a situation, the court is not likely to fail to recognise the existence of the records on the grounds that they are illegible. Moreover, in this case the possibility of using an API may allow the parties to observe smart contracts operating in coupling, through a party-friendly application. It also seems necessary to signal that the allegation that the parties will not understand the programming language is exaggerated. The parties may well not understand a specialist language such as a legal language expressed in a certain natural language. This is why contracts are increasingly being marketed using graphic symbols (simplification and visualisation), which can be understood even by people who cannot or do not fully use a certain natural language (see figure) $)^{35}$.

33 J. Huizinga, author of Homo ludens, is regarded as the creator of the concept of the magic circle. The concept of the magic circle is often used when considering virtual property - see Katie Salen and Eric Zimmerman, Rules of play: game design fundamentals (MIT Press 2003) 95. It is worth noting, however, that J. Huizinga himself seems to remain far from sceptical of this idea, while the actual originator of its adaptation is E. Zimmerman - see Eric Zimmerman, 'Jerked Around by the Magic Circle - Clearing the Air Ten Years Later' (Gamasutra, February 2012 $<$ https:/www.gamasutra.com/view/feature/135063/jerked_around_by_the_magic _circle_php> accessed 17 January 2021.

34 Dariusz Szostek (n 31) 116.

35 See Helena Haapio and Thomas D. Barton, 'Business-Friendly Contracting: How Simplification and Visualization Can Help Bring It to Practice' in Kai Jacob, Dierk Schindler and Roger Strathausen (eds), Liquid Legal (Springer 2017); see Gerlinde Berger-Walliser, Thomas D. Barton and Helena Haapio, 'From Visualization to Legal Design: A Collaborative and Creative Process' (2017) 54:2 American Business Law Journal 347. 
The same can be presented to the parties to a smart contract - in the form of mainly graphical signs ${ }^{36}$.

Figure 3. An example of Legal Design (exactly visualisation and simplification) from practice, where graphic signs were used instead of signs that make up a certain natural language, in this case the English legal language
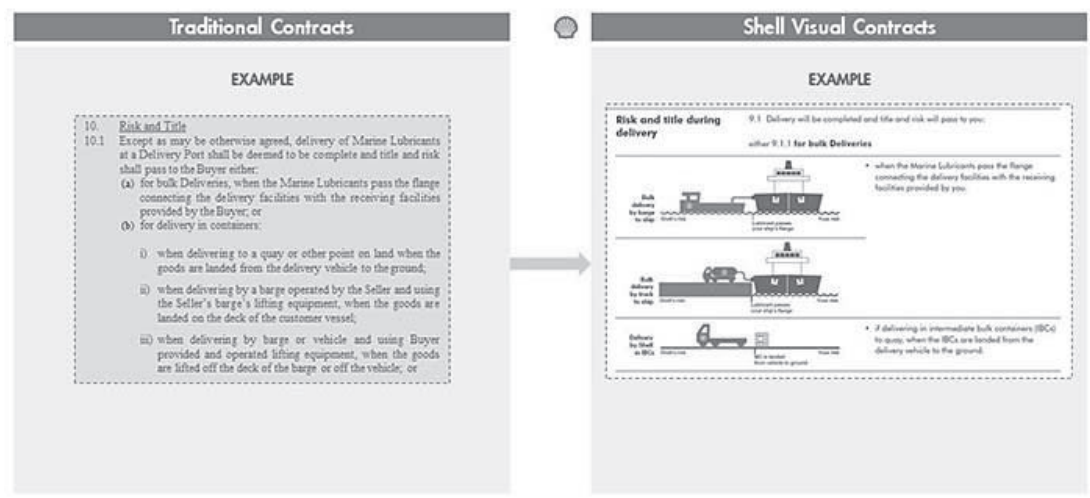

Source: https:/www.ft.com/content/032ddcb0-e6b1-11e9-b8e0-026e07cbe5b4

However, it should be emphasised that both the theoretical framework of the concept of a contract written in a language other than natural, i.e. smart contracts, and the undertaking of some limited developments of regulating the relationship between parties by means of codes were already taking place before the introduction of the Ethereum distributed registry. This can be observed, inter alia, in certain solutions for gamers in the game industry ${ }^{37}$. Solutions based on the automatic execution of contracts have already existed for many years in MMO games, particularly in the form of so-called auction houses, which act as automatic exchanges of virtual goods, where players can place bids to sell or buy goods. When another player accepts the offer, the system will automatically transfer the rights to the object of the transaction to the purchasing player, taking the appropriate amount of the in-game currency and assigning its value to

36 See O. S. Grin, E. S. Grin and A. V. Solovyov, The Legal Design of the Smart Contract: The Legal Nature and Scope of Application' (2019) 8 Lex Russia 51.

37 The mechanics of MMO games also seem to provide an important starting point for the theory of L. Lessig's theory, as evidenced by the many references contained in his book - see Lawrence Lessig, Code and Other Laws of Cyberspace. Version 2.0 (2nd revised edn, Basic Books 2006) 9. 
the selling player's account. At the same time, even in this type of games we can notice how the law is written in codes, because what the player and her/his virtual character can do, is limited to what the programmer envisaged at the stage of creating the code. It is therefore true that there are solutions where programming code replaces natural language, so that some representatives of the doctrine consider that such a program as a smart contract, is an alternative form of a legally binding $\operatorname{contract}^{38}$.

This observation is, however, quite controversial, in particular because the moment such a smart contract has been activated, a doubt arises immediately regarding the additional powers of the party ${ }^{39}$. This has led to the emergence of sharp criticism of blockchain-based solutions in international legal doctrine. On the one hand, there is the jellyfish perspective, which assumes that smart contracts that are heavily regulated, especially in the context of electronic data, will cease to thrive, just as a jellyfish, which after having been washed ashore, withers. The jellyfish perspective assumes that the implementation of N. Szabo's idea is not complete, and only the future will show how the concept of smart contracts will develop, i.e. whether contracts will actually become not only automatic, but also more complex and whether they will take into account more factors that influence the parties to the contract.

The second main problem arises from the need to transfer physical objects to the virtual realm (e.g. as part of so-called tokenisation). As long as digital goods, such as cryptocurrencies, remain the object of transaction, the transfer of "ownership" of such an object is technically not a problem. However, the dematerialisation of other assets is a significant challenge. In order to do an efficient transfer of ownership of a flat in the above manner, at the very least, a decentralised system of notarised property registry would be necessary. It is also possible to imagine installing smart locks in the flat that would verify the identity of their owner and fulfilling this realization appears much easier nowadays than in the earlier times ${ }^{40}$, but it still seems that creating a technically advanced system, while at the same time ensuring its sufficient openness (e.g. through API) and security

38 Stephen McJohn and Ian McJohn, 'The Commercial Law of Bitcoin and Blocktrain Transactions' (2016) 16-13 Legal Studies Research Paper Series Research Paper 15.

39 ibid.

40 Even so, it requires significant investment, which may not necessarily appear reasonable from the perspective of all owners. 
(bearing in mind particularly the DAO Hack ${ }^{41}$ ), can happen not to be so simple ${ }^{42}$.

\section{Tokenization of Assets}

Let us introduce the definition of "token". First of all, the linguistic interpretation of this word should be analysed. The etymology of the English word "token" allows us to conclude that it probably comes from the Old English word "tacen" which meant "sign, symbol, proof"43. The American Merriam-Webster dictionary defines „token” as „a piece resembling a coin issued for use by a particular group on specified terms" 44 . The Cambridge Dictionary indicates that it is a symbol, a paper worth money that can be exchanged for goods in a store, or a round metal or plastic disc that is used instead of money in various types of machines ${ }^{45}$. The Black's Law Dictionary proposed the same semantic explanation, as it defines token as a sign or symbol, being a material proof of a fact ${ }^{46}$. To sum up, the linguistic interpretation helps us to capture the essence of a token, i.e. its symbolism. However, it does not explain the legal implications of it. Therefore, it is necessary to make a further interpretation on the basis of the legal scholarship.

Michelle Finck defines token as an artificially produced digital good, recorded through blockchain, which, due to the nature of the system, can only be used once ${ }^{47}$. In our opinion, the aforementioned definition seems

41 Samuel Falkon, "The Story of the DAO - Its History and Consequences" (Medium, December 2017) <https://medium.com/swlh/the-story-of-the-dao-its-history-a nd-consequences-71e6a8a551ee> accessed 19 January 2021.

42 Focusing our attention at least for a moment on the economic analysis of law, it is impossible not to mention here also the total redundancy of notaries in such a system. See Jeff Lingwall and Ramya Mogallapu, 'Should Code Be Law? Smart Contracts, Blockchain, and Boilerplate' (2019) 88:1 University of Missouri-Kansas City Law Review 311.

43 'Token', Online Etymology Dictionary <https:/www.etymonline.com/word/token> accessed 2 February 2021.

44 'Token', Merriam-Webster Dictionary <https://www.merriam-webster.com/dictiona ry/token $>$ accessed 2 February 2021.

45 'Token', Cambridge Dictionary < https://dictionary.cambridge.org/dictionary/englis h/token $>$ accessed 2 February 2021.

46 Henry C. Black, 'Token', The Black's Law Dictionary (Rev $4^{\text {th }}$ edn, West Publishing Co. 1968) 1658.

47 Michèle Finck, Blockchain Regulation and Governance in Europe (CUP 2018) 16, which relies on Jean Bacon, Johan David Michels, Christopher Millard and Jatinder 
to be too narrowed down to the concept of blockchain, and it is possible for token to exist without this technology ${ }^{48}$. Nevertheless, this definition is a good starting point for further considerations. More broadly and universally speaking, token can be defined as a digital good representing values or rights, within or outside the DLT register. However, it should be borne in mind that tokens exist and have value primarily within their system ${ }^{49}$, hence they are usually used in individual business models, without intermediaries and entities facilitating the distribution of the product ${ }^{50}$.

We can distinguish two different aspects of the value of tokens ${ }^{51}$. Firstly, they can have exclusive value only within their blockchain. Secondly, they can be an avatar of real assets, such as goods (e.g. gold ${ }^{52}$ or medical marijuana ${ }^{53}$ ), services (e.g. dental services ${ }^{54}$ ), or specific rights (e.g. economic copyrights ${ }^{55}$ ).

Singh, 'Blockchain Demystified' (2017) 268/2017 Queen Mary School of Law Legal Studies Research Paper 5 <https://ssrn.com/abstract=3091218> accessed 6 February 2021. See also regarding feature of one-time use Satoshi Nakamoto, 'Bitcoin: A Peer-to-Peer Electronic Cash System' $1<$ https://bitcoin.org/bitcoin.pdf $>$ accessed 8 February 2021.

48 Szostek (n 31) 126.

49 Stefan Tönnissen, Jan Heinrich Beinke, Frank Teuteberg, 'Understanding Token-based Ecosystems - a Taxonomy of Blockchain-based Business Models of Start-ups' (2020), 30 Electron Markets 307, 309 <https://doi.org/10.1007/s12525-020 -00396-6> accessed 8 February 2021.

50 William Mougayar, 'Tokenomics - A Business Guide to Token Usage, Utility and Value' (Medium, 10 June 2017) <https://medium.com/@wmougayar/tokeno mics-a-business-guide-to-token-usage-utility-and-value-b19242053416> accessed 6 February 2021.

51 Finck (n 47) 10.

52 For example, PAX Gold, which is a cryptocurrency, where each token is secured by one troy ounce, the holder of which becomes the owner of the physical gold held by a trust company. See. <https://www.paxos.com/paxgold/> accessed 6 February 2021.

53 For example, CannabisCoin (CANN), it is a cryptocurrency created in 2014, the purpose of which was to directly exchange 1 token for 1 gram of medical marijuana. See. <https://www.investopedia.com/news/top-marijuana-cryptocurren cies/> accessed 6 February 2021.

54 For example, dentacoin cryptocurrency. See: $<$ https://dentacoin.com/ $>$ accessed 6 February 2021.

55 For example, KodakCoin. It is a cryptocurrency created by a famous manufacturer of cameras that allows the photographer to manage his copyrights to photos, license them and collect remuneration for it.. See: David Gerard, 'The KodakCoin ICO failed, and now everyone wants their money' (David Gerard, 10 December 2018) <https://davidgerard.co.uk/blockchain/2018/12/10/the-kodakcoin-ico-f ailed-and-now-everyone-wants-their-money/> accessed 6 February 2021 and 
The first type of the value of token, as undoubtedly more abstract, requires a deeper explanation. Cryptocurrencies will be an example of such an asset, including the most famous of them bitcoin, and, perhaps a more glaring example, Dogecoin ${ }^{56}$, a joke cryptocurrency created in 2013 and inspired by the once-famous meme with a shiba inu dog, known as a "doge". Dogecoin has basically no value in the traditional sense and neither it is the equivalent of anything real, nor it is secured by a state monopoly. It does not change the fact that its market capitalization is currently close to $\$ 6.5$ billion, and the value of one Dogecoin has reached the level of 5 cents $^{57}$, while it initial value was 0.03 cents $^{58}$. Another, but also a thought-provoking example of this phenomenon is the digital work entitled "The First 5000 days" created by an artist nicknamed Beeple (Mike Winkelman), which is a non-fungible token, sold at Christie's for \$ 69.3 million ${ }^{59}$.

$<$ https://www.ryde.one/> accessed 6 February 2021. See also: Balazs Bodo, Daniel Gervais, Joao Pedro Quintais, 'Blockchain and Smart Contracts: the Missing Link in Copyright Licensing?’ (2018) 26 International Journal of Law and Information Technology $311<$ https://academic.oup.com/ijlit/article/26/4/311/5106727> accessed 7 February 2021; Michele Finck, Valentina Moscon, 'Copyright Law on Blockchains: Between New Forms of Rights Administration and Digital Rights Management 2.0.' (2019) 50 IIC - International Review of Intellectual Property and Competition Law 77; Annabel Tresise, Jake Goldenfein and Dan Hunter, 'What Blockchain Can and Can't Do for Copyright' (2018) 28 Australian Intellectual Property Journal $144<$ https://ssrn.com/abstract $=3227381>$ accessed 7 February 2021.

$56<$ https://dogecoin.com/> accessed 6 February 2021.

$57<$ https:/www.coingecko.com/pl/waluty/dogecoin> accessed 6 February 2021.

$58<$ https://finance.yahoo.com/quote/DOGE-USD/> accessed 6 February 2021.

59 Hannah Denham, Gerrit De Vynck and Rachel Lerman, 'What is an NFT, and how did an artist called Beeple sell one for $\$ 69$ million at Christie's?' The Washington Post (Washington D.C., 12 March 2021) < https://www.washingtonpost.c om/technology/2021/03/12/nft-beeple-christies-blockchain/> accessed 15 March 2021. 
From the legal point of view, token raises many doubts, which mainly concern financial law and trading security ${ }^{60}$, hence the vast majority of global regulations apply to this matter ${ }^{61}$.

However, the main problem related to tokens is the phenomenon of tokenisation. By tokenisation we mean a process of representing a given value (goods, services or rights) as a unit of account within or outside the DLT register ${ }^{62}$. This process is mostly carried out by an Initial Coin Offering (ICO), which is a fundraising technique of blockchain-based tokens sale in exchange for cryptocurrency or fiat money with the aim to collect financial support for a given initiative ${ }^{63}$.

It is worth emphasizing that "smart contracts" play also important role in tokenisation as tokens offered in the ICO are most often distributed through smart contracts. ${ }^{64}$ To put it simply, since such contracts are selfexecuting, they automatically exchange cash or other cryptocurrencies for tokens of a given publisher ${ }^{65}$. However, smart contracts are usually much more complicated and subject to additional conditions, e.g. they enable the fastest investors to receive an additional $5 \%$ of tokens or they make the payment dependent on collecting a predetermined minimum amount ${ }^{66}$.

60 See more Robby Houben and Alexander Snyers, 'Cryptocurrencies and blockchain. Legal context and implications for financial crime, money laundering and tax evasion', (European Parliament's Special Committee on Financial Crimes, Tax Evasion and Tax Avoidance 2018), <https:/www.europarl.europa.eu/cmsdata /150761/TAX3\%20Study\%20on\%20cryptocurrencies\%20and\%20blockchain.pdf $>$ accessed 8 February 2021.

61 The topic will be elaborated on in the third subchapter "Comparative Legal Analysis of Selected Regulations Regarding the Token. Will the European Union Synthesize It? ".

62 See: Omri Ross, Jihanes Rude Jensen and Truls Asheim, 'Assets under Tokenization' (2019) <https://ssrn.com/abstract=3488344> accessed 9 March 2021.

63 Alexis Collomb, Primavera De Filippi and Klara Sok, 'Blockchain Technology and Financial Regulation: A Risk-Based Approach to the Regulation of ICOs' (2019) 10 European Journal of Risk Regulation 263, 264 <doi:10.1017/ err.2019.41> accessed 9 March 2021.

David Uzsoki, 'Tokenization of Infrastructure: A blockchain-based solution to financing sustainable infrastructure, (International Institute for Sustainable Development 2019) 2 <doi:10.2307/resrep22004.3> accessed: 9 March 2021.

64 Szostek (n 31) 127.

65 Valentina Gatteschi, Fabrizio Lamberti and Claudio Demartini, 'Technology of Smart Contracts' in Larry DiMatteo, Michel Cannarsa, Cristina Poncibò (eds), The Cambridge Handbook of Smart Contracts, Blockchain Technology and Digital Platforms (CUP 2019) 45 <doi:10.1017/9781108592239.003> accessed 9 March 2021.

66 ibid. 


\subsection{Types of Tokens - the Basic Knowledge of Every Legal Engineer}

In principle, tokens can represent any value or any right ${ }^{67}$. However, because of their functions, both legislators and legal scholarship try to typologise them, as the application of certain legal provisions depends on their characteristics. The most popular typology is the following one ${ }^{68}$ :

1) Exchange tokens (known also as cryptocurrencies or payment tokens) - tokens used primarily as a means of payment used to buy and sell goods and services without intermediaries; an example of such tokens are bitcoin or Ethereum ${ }^{69}$;

2) Utility tokens - tokens that grant its holders access to a current or potential product or service, but do not grant them the same rights as those granted by specific investments. Examples of such tokens are Golem $(\mathrm{GNT})^{70}$, which allows to access specific computing power resources, or Filecoin (FIL) ${ }^{71}$, which enables to store information;

3) Security tokens (known also as ,asset tokens" or "investment tokens”) tokens with specific properties, like rights and obligations similar to stocks or financial instruments, with a largely similar function as stocks or bonds. According to R. Houben and A. Snyers ${ }^{72}$, an example of such a token is the "BNK token" by Bankera, which gives its holder the right to a weekly dividend of 50 Ethereum.

67 Finck (n 47) 16.

68 See: Financial Conduct Authority, 'Guidance on Cryptoassets Feedback and Final Guidance to CP 19/3' (2019) 4 <https://www.fca.org.uk/publication/policy/ps19-2 2.pdf $>$ accessed 7 February 2021; FINMA, 'Guidelines for enquiries regarding the regulatory framework for initial coin offerings (ICOs)' (2018) 3, <https://www.fin ma.ch/en/ /media/finma/dokumente/dokumentencenter/myfinma/1bewilligung /fintech/wegleitung-ico.pdf?la=en $>$ accessed 7 February 2021; EBA, 'Report with advice for the European Commission on crypto-assets' (2019) 7. See also similar recital 10 of Comission, 'Proposal for a Regulation Of The European Parliament and of the Council on Markets in Crypto-assets, and amending Directive (EU) 2019/1937', (2020) COM/2020/593 final.

69 Sometimes this type of tokens stands out as a separate category due to their popularity, simply calling them cryptocurrencies. See: Robby Houben and Alexander Snyers, 'Crypto-assets. Key developments, regulatory concerns and responses' (European Parliament's Committee on Economic and Monetary Affairs 2020), $18<$ https://www.europarl.europa.eu/RegData/etudes/STUD/2020/648779/IPOL_STU( 2020)648779_EN.pdf $>$ accessed 7 February 2021

$70<$ https://golem.network/> accessed 7 February 2021.

$71<$ https://www.filecoin.com/> accessed 7 February 2021.

72 Houben and Snyers (n 60) 21. 


\subsection{Comparative Legal Analysis of Selected Regulations Regarding the Token. Will the European Union Synthesise It?}

Regulations regarding tokens can be divided into two main types. The first one is the regulation of cryptocurrencies through money laundering legislation, and the second one is the regulation of payment services, either by creating new service laws or by issuing binding interpretations by the regulator. There is also a group of countries that regulate the issue of tokens and tokenisation in both of these regulatory areas. The EU (and thus its Member States) ${ }^{73}$, Great Britain ${ }^{74}$, Liechtenstein ${ }^{75}$ and Switzerland ${ }^{76}$ are all in the first group.

Among the EU Member States, Malta is worth paying particular attention to, as this state was a pioneer of crypto industry legislation on the European continent. The Maltese regulation comprises in three legal acts: Virtual Finacial Assets Bill (VFA) ${ }^{77}$, Innovative Technology Arrangements and Services Bill (ITASA) $)^{78}$ and Malta Digital Innovation Authority Bill $(\text { MDIA })^{79}$. They constitute legal framework for the functioning of digital economy based on DLT and blockchain and for activities involving tokens

73 This was done by 90. Directive 2018/843 of European Parliament and of the Council of 30 May 2018 amending Directive 2015/849 on the prevention of the use of the financial system for the purposes of money laundering or terrorist financing, and amending Directives 2009/138/EC and 2013/36/EU [2018] OJ L156/43, hereinafter referred to as AMLD5.

74 The Money Laundering and Terrorist Financing (Amendment) Regulations 2019, implementing AMLD5.

75 Act on Professional Due Diligence to Combat Money Laundering, Organized Crime, and Terrorist Financing (Gesetz über berufliche Sorgfaltspflichten zur Bekämpfung von Geldwäscherei, organisierter Kriminalität und Terrorismusfinanzierung (Sorgfaltspflichtgesetz), Landesgesetzblatt Nummer (O.J. 2009, no 47 with amendments) <https://www.gesetze.li/konso/pdf/2009047000?version=19> accessed 7 February 2021, see unofficial English translation $<$ https://www.regierung.li/media /medienarchiv/952_1_17_11_2017_en_636524807784985165.pdf?t=5 > accessed 7 February 2021.

76 It is worth remembering, however, that in Switzerland such application of antimoney laundering provisions was not determined directly by the legislator, but by the Swiss financial market supervisory authority (i.e. Swiss Financial Market Supervisory Authority - FINMA). See. FINMA (n 68).

$77<$ http://justiceservices.gov.mt/DownloadDocument.aspx?app=lp\&itemid=29079\&l $=1>$ accessed 7 February 2021 .

$78<$ http://justiceservices.gov.mt/DownloadDocument.aspx?app=lp\&itemid=29078\&l $=1>$ accessed 7 February 2021.

$79<$ http://justiceservices.gov.mt/DownloadDocument.aspx?app=lp\&itemid=29080\&l $=1>$ accessed 7 February 2021. 
and smart contracts. For example, Art. 2 of VFA defines the term "virtual tokens" as „a form of digital medium recordation that has no utility, value or application outside of the DLT platform on which it was issued and may only be redeemed for funds on such platform directly by the issuer of such DLT asset". Thus, the Maltese regulations can be assigned to both above-mentioned groups.

The United States of America is an unusual regulator, as due to the federal nature of the state, it has left the regulation of cryptocurrencies to individual States. Not all States have legally regulated the operation of the crypto industry. In some of them (e.g. in Florida ${ }^{80}$ ) case-law, established by either judicial or regulatory authorities, has the key role. On the other hand, the provisions introduced in the State of New York deserve special attention. Model regulation based on the law of payment services has been introduced there, requiring from entities involved to obtain a special license ${ }^{81}$.

Similar solutions were adopted by, for example, Belarus, which decided to regulate the entire activity of cryptocurrencies and tokens, including their exchange, as a type of payment services ${ }^{82}$.However, the Belarusian regulation does not apply to the entire territory of the country, but only to residents of the Park of High Technologies. Obtaining such a status requires the undertaking to apply in advance for a registration in the Supervisory Board of the Park, in accordance with the Decree of the President of the Republic of Belarus of September 22, 2005 No. 12, constituting the Regulations of the Park of High Technologies ${ }^{83}$. The second group

80 This concerns, in particular, the verdict in the Florida v. Espinoza case, which indicated the need to adapt the statutory regulations of the state of Florida in the field of payment services to new technologies. See. Florida v Espinoza, Case No F14-2923 (Fla 11th Cir Ct) <https://www.morrisoncohen.com/siteFiles/fil es/2014_02_06\%20-\%20Florida\%20v_\%20Espinoza.pdf > accessed 7 February 2021; Florida v. Espinoza, Case No. 3D16-1860; Gabrielle Patrick and Anurag Bana, 'Report. Rule of Law Versus Rule of Code: A Blockchain-Driven Legal Word' (2017) International Bar Association Legal Policy \& Research Unit 16.

81 See: Bitlicense (2020) 23 CRR-NY I 200, <https:/govt.westlaw.com/nycrr/Browse/ Home/NewYork/NewYorkCodesRulesandRegulations?guid=I7444ce80169611e59 4630000845 b8d3e\&originationContext=documenttoc\&transitionType=Default\& contextData $=($ sc.Default $)>$ accessed 7 February 2021.

82 See: Decree of the President of the Republic of Belarus from 21.12.2017, No. 8 On Development of Digital Economy $<$ http://law.by/document/?guid=3871\&p0=Pd1 700008 e $>$ accessed 7 February 2021.

83 In the amended version after entry into force of Decree of the President of the Republic of Belarus from 21.12.2017, No. 8 On Development of Digital Econo- 
should also include Singapore ${ }^{84}$ and Japan ${ }^{85}$, as in both countries token trading was regulated by amendments to previously proclaimed acts on payment services.

It is also worth noticing that the research conducted recently by the $\mathrm{EU}^{86}$ indicates that the development of the crypto industry has overtaken the EU legislator and it has become necessary to introduce a new law aimed at regulating cryptoassets, i.e. broadly understood cryptocurrencies and tokens ${ }^{87}$. The solution to this problem will be Regulation of the European Parliament and of The Council on Markets in Crypto-assets, and amending Directive (EU) 2019/1937, which is currently a proposal. As Ursula von der Leyen, President of the European Commission pointed out, the purpose of the regulation is to create "a common approach with Member States on cryptocurrencies to ensure we understand how to make the most of the opportunities they create and address the new risks they may pose" 88 . By the above-mentioned normative act, the European Commission is trying to regulate the crypto assets, including tokens, in a holistic manner, by following the legal scholarship and distinguishing three types of tokens: tokens associated with assets (which correspond to investment tokens), utility tokens and crypto-assets (exchangeable tokens) ${ }^{89}$. This proposal should therefore be seen as a necessary step in the right direction.

my, <http://law.by/document/?guid=3871\&p0=Pd1700008e $>$ accessed 7 February 2021.

84 Singapore's Payment Services Bill No. 48/2018<https://sso.agc.gov.sg/Bills-Supp/4 8-2018/Published/20181119?DocDate=20181119\#Sc1-> accessed 7 February 2021.

85 Japanese Act No. 59 of June 24, 2009 on Payment Services. See English translation: $<$ http://www.japaneselawtranslation.go.jp/law/detail/?id=3078\&vm=02\&re= 02e\&new $=1>$ accessed 7 February 2021.

86 The last and most up-to-date feature is the 'Consultation Document on an EU framework for markets in crypto-assets' presented by the European Comission. See: <https://ec.europa.eu/info/sites/info/files/business_economy_euro/bankin g_and_finance/documents/2019-crypto-assets-consultation-document_en.pdf> accessed 8 February 2021.

87 Houben and Snyers (n 60) 48.

88 Mission letter of President-elect Von der Leyen to Vice-President Dombrovskis (10 September 2019) <https://multimedia.europarl.europa.eu/documents/20143/0 /mission-letter-valdis-dombrovskis-2019_en+\%281\%29.pdf/d3645133-8c2e-7fdd-43 67-77059b892232?t=1569412036000\&download=true > accessed 15 March 2021.

89 See recital 9 and Art. 2 of the discussed proposal. However, it would be suggested to change the nomenclature of the latter subgroup, as it coincides with the name of the entire group (this problem occurs at least in Polish, English, French and German versions). 


\subsection{What about Lawyers When the Code Becomes Law? Selected Legal Challenges of Tokenisation}

So what a lawyer can do in the face of such tokenised future? The tokenisation itself, usually reduced to blockchain technology, can undoubtedly be called a technology that is autonomous in relation to the law, and certainly is not adapted to it $^{90}$. It is no coincidence that blockchain is usually referred to as a disruptive and revolutionary technology ${ }^{91}$. It creates new markets but it destroys current states, companies and networks at the same time ${ }^{92}$. However, this is a double-edged mismatch because the law is also not adjusted to the technology mentioned above. Moreover, the law is mismatched in a way in which it loses. On the line of mismatch between technology and law and in the new markets created the most tasks for lawyers open up.

Such a task would be, for example, finding of the applicable law to which the token will be subject given that there are no international standards on this matter ${ }^{93}$. In most cases, due to the tokens trade in cyberspace, the norms of private international law will enter into the civil law

90 Matthias Lehmann, 'Who Owns Bitcoin? Private Law Facing the Blockchain' (2019) 21 Minnesota Journal of Law, Science \& Technology 93, $107<$ https://schol arship.law.umn.edu/cgi/viewcontent.cgi? article $=1474 \&$ context $=$ mjlst $>$ accessed 15 March 2021.

91 See: Michael Nofer, Peter Gomber, Oliver Hinz and Dirk Schiereck, 'Blockchain' (2017) 59 Business \& Information Systems Engineering $183<$ doi 10.1007/s 125 99-017-0467-3> accessed 15 March 2021; Lawrence J Trautman, 'Is Disruptive Blockchain Technology the Future of Financial Services?' (2016) 69 The Consumer Finance Law Quarterly Report 232, $239<$ https://ssrn.com/abstract=27861 86> accessed 15 March 2021; Sinclair Davidson, Primavera De Filippi and Jason Potts, 'Disrupting Governance: The New Institutional Economics of Distributed Ledger Technology' (2016), 2-5, <http://dx.doi.org/10.2139/ssrn.2811995> accessed 9 March 2021.

92 We use this meaning after: Joseph. L Bower and Clayton M Christiensen, 'Disruptive Technologies: Catching the Wave' (January-Februrary 1995) Harvard Business Review 43 <https://hbr.org/1995/01/disruptive-technologies-catching-the-wav e> accessed 2 February 2021.

93 Riccardo de Caria, 'A Digital Revolution in International Trade? The International Legal Framework for Blockchain Technologies, Virtual Currencies and Smart Contracts: Challenges and Opportunities' (Modernizing International Trade Law to Support Innovation and Sustainable Development Proceedings of the Congress of the United Nations Commission on International Trade Law, Vienna, July 2017) <https://aperto.unito.it/retrieve/handle/2318/1632525/464608/R.\%20de\% 20Caria\%2c\%20A\%20Digital\%20Revolution\%20\%282017\%29.pdf> accessed 2 February 2021. 
relations of the parties. If the parties have not chosen the law applicable (e.g. in the case of contractual tokens trade), which happens in the vast majority of cases, then legal norms applicable to the habitual residence of the party obliged to the so-called characteristic performance will apply ${ }^{94}$. However, it may not be possible to apply this standard to token trading due to the anonymity of such a blockchain transfer, in which neither party knows the other participant or its address ${ }^{95}$. Perhaps the problem could be solved by the closest connection connecting factor, although it is neither the most reliable nor the objective one ${ }^{96}$. In addition, the application of CISG cannot be ruled out for some transactions with the use of tokens if they constitute remuneration for the sale of real goods between entrepreneurs ${ }^{97}$. Furthermore, determining the law applicable to the "ownership" of a token may be found similarly problematic ${ }^{98}$.

As we have indicated earlier, problems requiring legal solutions will also arise due to the mismatch between the law and the characteristics of tokens and blockchain technology. The technical feasibility of the law applicable to tokens within the DLT is also becoming a serious issue. In some cases, especially those related with enforcement, the law will be ineffective, as token usually eludes it both in the legal sense and in the sense of technical feasibility. Not knowing the password (i.e. private key), it is impossible to get to the given tokens. For example, let us consider the situation of would-be millionaire James Howell who threw away his old hard drive on which he gathered 7,500 bitcoins (currently worth about GBP 210 million)

94 See. art. 4 (2) Regulation (EC) No 593/2008 of the European Parliament and of the Council of 17 June 2008 on the law applicable to contractual obligations (Rome I) [2008] O. J. L 177/6.

95 Lehmann (n 114) 15.

96 See: Florence Guillaume, 'Aspects of private international law related to blockchain transactions' in Daniel Kraus, Thierry Obrist and Olivier Hari (eds), Blockchains, Smart Contracts, Decentralised Autonomous Organisations and the Law (Edward Elgar 2019) 82, which indicates that in most cases due to the inability to use other connecting factors the lex fori principle will apply. See also: Szostek, (n 31) 68-80 as regards the indication of the copyright law applicable to Bitcoin blockchain copyright and Bitcoin agreements.

97 See: United Nations Commission on international trade law, 'United Nations Convention on Contracts for the International Sale of Goods' (1980) < https://un citral.un.org/sites/uncitral.un.org/files/media-documents/uncitral/en/19-09951_e _ebook.pdf> accessed 2 February 2021. See also: Sebastian Omlor, 'The CISG and libra: monetary revolution for international commercial transactions?' (2020) 3(1) Stanford Journal of Blockchain Law \& Policy 83-95.

98 Lehmann (n 90) 16-17. 
and is looking for it in a landfill99. The same goes for German prosecutor's office, which recently "confiscated" EUR 50 million worth of bitcoins ${ }^{100}$. However, there was one problem. The former owner of these bitcoins, now convicted of fraud, does not intend to reveal his private key to the prosecutor. Therefore, the prosecutor's office has to rely on the grace and disfavour of the convict. As Chainanalysis, a cryptocurrency data research firm, points out, about $20 \%$ of bitcoins, worth a total of USD130 billion, appear to be lost forever due to the loss of private keys by their owners.

Courts will also have to deal with the above-mentioned technology in terms of the appropriate treatment of evidence presented in court proceedings on an undeniable medium such as blockchain ${ }^{101}$. Such evidence had already been submitted and processed by the Chinese Internet Court in June 2018 in the case Hangzhou Huatai Media Culture Media Co., Ltd. v. Shenzhen Daotong Technology Development Co., Ltd. ${ }^{102}$ This issue was directly regulated three months later in the provisions of the Supreme Court of the People's Republic of China concerning the hearing of cases by internet courts ${ }^{103}$. However, the Chinese legislator was not the first to regulate this problem, because e.g. Vermont and Arizona were faster to introduce such rules in 2016 and 2017 respectively ${ }^{104}$.

$99<$ https://www.bbc.com/news/uk-wales-55658942> accessed 9 February 2021.

$100<$ https://www.reuters.com/article/us-crypto-currency-germany-password/police-se ize-60-million-of-bitcoin-now-wheres-the-password-idINKBN2A511T $>$ accessed 9 February 2021.

101 See: Szostek (n 31) 97-108.

102 See: 'Hangzhou Huatai Media Culture Media Co., Ltd. v. Shenzhen Daotong Technology Development Co., Ltd. Case of Dispute over Right of Dissemination over Internet' (The Supreme People's Court of the People's Republic of China, 4 April 2019) <http://english.court.gov.cn/2019-12/04/content_37527759.htm $>$ accessed 9 February 2021. See also: Raphael Prabucki, 'About Chinese Courts and Blockchain - A Simple Chain Foundation commentary' (Medium, 18 June 2020)<https://medium.com/@prabucki.rafael/chinese-justice-and-blockchain-wh at-can-we-learn-ed4285e1a34d $>$ accessed 9 February 2021.

103 Vivien Chan and Anna Mae Koo, 'Blockchain Evidence in Internet Courts in China: The Fast Track for Evidence Collection for Online Disputes' (Lexology, 15 July 2020) <https://www.lexology.com/library/detail.aspx?g=1631e87b-15 5a-40b4-a6aa-5260a2e4b9bb $>$ accessed 9 February 2021. See: Sylvia Polydor, 'Blockchain evidence in court proceedings in China a comparative study of admissible evidence in the digital age (as of june 4, 2019)' (2020) No. 3(1) Stanford Journal of Blockchain Law \& Policy 96.

104 See more in the further chapter by Agnieszka Kubiak-Cyrul, Dariusz Szostek, 'Smart Contracts, Blockchain and Distributed Ledger Technology (DLT) in the Work of a Lawyer'. 
Michelle Finck also points to another very interesting, revolutionary and at the same time threatening tokenisation feature, associated with utility tokens ${ }^{105}$. Due to the ease and certainty of transferring ownership over the token in the blockchain chain, we risk a liquid and intermediary-less (sometimes a system fuse, such as notaries under real estate law) "transferring" real estate ownership, intellectual property or any other property right across the whole world ${ }^{106}$. The increasing popularity of this phenomenon will therefore most likely lead to a deepening gap between applicable laws and jurisdiction. Thus, we can encounter an increasing number of activities effective within the framework of a distributed register but invalid or ineffective in legal reality. This situation will not be beneficial for either party. This leads to the conclusion that tokens will have to be adjusted to the law, not the law to tokens.

\section{Control of Codes and LegalTech}

\subsection{Introduction}

Equally important is the issue of control over codes. Undoubtedly, taking smart contracts as an example, it would have to be said that any particular control is in contradiction not only with their nature but with the essence of DLT technology ${ }^{107}$ as well, which should be deduced from the fact that this solution eliminates the need for a trusted third party (e.g. interference of a legally established public trust institution such as a notary, bank, etc.). The absence of intermediaries and the risk of contract default constitute the main advantages of smart contracts, but at the same time they are also their biggest disadvantages. Smart contract operate as programming code, which means that they are automatically executable ${ }^{108}$. As a result

105 Finck (n 47) 18.

106 Wright and De Filippi (n 4) 28.

107 As stated in the description of Solidity on GitHub: "Smart contracts are programs that are executed inside a peer-to-peer network where nobody has special authority over the execution, and thus they allow to implement tokens of value, ownership, voting, and other kinds of logic", <https://github.com/ethereum/soli dity> accessed 6 February 2021).

108 However, when talking about contracts here, the vast majority of such contracts will be of an adhesion nature. For example, in a sales contract, the buyer, by sending the appropriate instruction, will accept the offer and enter into the contract, which will be self-executing. See D. Szostek, (n 5). 
the parties to such transactions have to rely primarily on the developer of the code.

The question then arises whether something whose main feature is the limitation of control in the perspective of traditional law (territory, applicable law, court) should be controlled? According to current legislative trends in the EU, it cannot be considered sufficient to give complete freedom in this respect, relying on the parties' extensive contractual rights ${ }^{109}$. In all likelihood, the Code does not exist in a legally irrelevant vacuum either. The ITU has provided a universal legal control key based on the possible control of codes in DLTs (Figure $4^{*}$ ).

109 With regard to general code control, the above need assumes particular importance, inter alia, in the context of the European Commission's recent decision on its preliminary opinion on Amazon's restrictive practices, $<$ https://ec.europa.e u/commission/presscorner/detail/en/ip_20_2077> accessed 6 February2021); Undoubtedly, the lack of appropriate interference by legislators with the increasing prevalence of artificial intelligence algorithms used to gain competitive advantage will lead to a gradual monopolisation of markets. For more on the potential for abuse of algorithms, see the report: Competition and Markets Authority (UK), 'Algorithms: How they can reduce competition and harm consumers' (Crown, 2021) <https://assets.publishing.service.gov.uk/government/uploads/ system/uploads/attachment_data/file/954331/Algorithms_++.pdf $>$ accessed 19 January 2021.

* Source: Own elaboration based on the International Telecommunication Union, Technical Report FG DLT D4.1 Distributed ledger technology regulatory framework, 2019. 
Rafat Prabucki, Rafat Skibicki, Dariusz Szostek, Jakub Wyczik

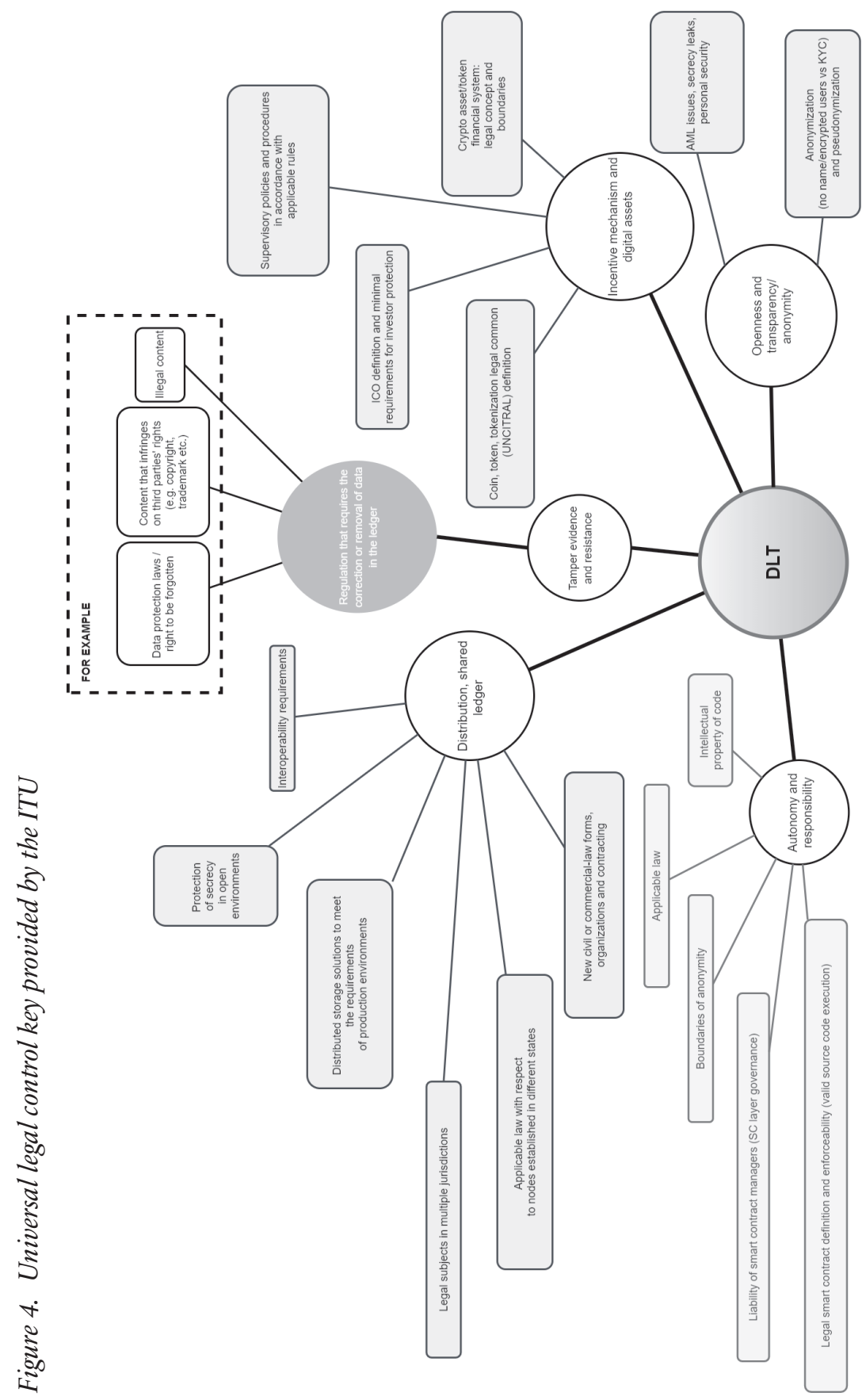


This issue is becoming more and more essential in LegalTech, which has implications for the security of legal transactions. In view of this, it would be more appropriate to ask: how should the technology and the codes be controlled? Should we require disclosure of the algorithms hidden in the codes of LegalTech systems? What new regulations should be adopted to ensure cyber security? Or should some of the existing regulations simply be extended? Undoubtedly, the elaboration of the above issues deserves a separate even more detailed study, but the purpose of this piece is to give them a general consideration and to highlight selected issues ${ }^{110}$.

Alison Hook presented her 2019 report on the use and regulation of LegalTech ${ }^{111}$. The author identified four leading approaches that can be seen amongst current regulatory trends ${ }^{112}$ :

1) Most countries adopt what has been termed a "wait and see" approach. The plethora of other regulatory obligations and the prioritisation of issues with limited resources means that the legal approach to LegalTech is not a leading theme in legislative work. All the more so, it does not receive much attention in the area of soft regulation either;

2) There are sometimes cases where lawyers are even prohibited from using such technologies, for example by restricting their access to the market for online legal services. There is a tendency to impose a kind of LegalTech prohibition ${ }^{113}$;

3) he third approach is based on an attempt to extend current regulations to cover the problem of control of the LegalTech sector. Moreover, some legal authorities have led to the acquisition of providers of such technologies or they have even been given the opportunity to influence

110 Particularly noteworthy in this regard is the expert opinion of: Mario Martini 'Fundamentals of a Regulatory System for Algorithm-based Processes' (2019) $<$ https://www.vzbv.de/sites/default/files/downloads/2019/07/19/martini_regulato ry_system_algorithm_based_processes.pdf $>$ accessed 18 November 2020 .

111 Alison Hook, 'The Use and Regulation of Technology in the Legal Sector beyond England and Wales. Research Paper for the Legal Services Board' (Hook Tangaza, 2019) <https://www.legalservicesboard.org.uk/wp-content/uploads/2019 /07/International-AH-Report-VfP-4-Jul-2019.pdfhttps://www.legalservicesboard.o rg.uk/wp-content/uploads/2019/07/International-AH-Report-VfP-4-Jul-2019.pdf accessed 16 March 2021.

112 ibid 8.

113 Already in 2010, the Taiwan Bar Association banned its members from participating in online legal services exchanges on the grounds that they violated the Bar Code of Ethics, under the pretext of the dangers of referral fees. For more examples see: ibid 34 . 
the development of such technologies to ensure their compliance with current regulations ${ }^{114}$;

4) Finally, there are several cases of jurisdictions that have made efforts and attempted to facilitate access to the legal sector by allowing IT players to enter it through the support of local government bodies and by opening a dialogue to coordinate cross-sectoral cooperation ${ }^{115}$.

However, it should be stressed that the right approach and the use of a key by the creators of a certain DLT, which would comply with a certain legal system, makes it possible to obtain a DLT in which each code would be somewhat controlled in such a perspective that it is the algorithmic code that creates the DLT data (that is, e.g., the way it is managed, the number of access layers) that would control the program code written in it ${ }^{116}$. This process, however, requires legal knowledge in order to relate the ITU key to the applicable laws in a certain system ${ }^{117}$.

\subsection{Prior control}

At present, however, there are no hard legal solutions apparent at the European level, hence - as it has been indicated above - the approach to the scope in discussion varies significantly from country to country. European regulations to date do not in any way harmonise the rules on the provision of legal services beyond what is applicable to all service providers, in particular as regards the automated processing and profiling of personal data under the GDPR ${ }^{118}$. Work on the first draft code regulations is still in progress.

114 A classic example of this is the CloudLawyers portal, an online marketplace for legal services created in partnership with American Bar Association, <https://www. zeekbeek.com> accessed 16 March 2021.

115 See LegalFuel <https://www.legalfuel.com> accessed 16 March 2021; Future Law Innovation Programme <https://www.flip.org.sg> accessed 16 March 2021; Abogacía Española <https://www.abogacia.es/servicios> accessed 16 March 2021.

116 Szostek (n 29) 15.

117 As K. Werbach notes - developers need to consider both codes and incorporate them - both programmatic and legal. See Kevin Werbach, 'Trust, But Verify: Why the Blockchain Needs the Law' (2019) 33/2 Berkeley Technology Law Journal 497.

118 See 131. Martin Ebers, 'Legal Tech and EU Consumer Law' in: Larry A. DiMatteo, André Janssen, Pietro Ortolani, André Janssen, Pietro Ortolani, Francisco de Elizalde, Francisco de Elizalde, Michel Cannarsa, Mateja Durovic (eds), Lawyering in the Digital Age (Cambridge University Press 2021). 
Current trends in the harmonisation of the market for algorithms in the EU are well illustrated by three reports which are European Parliament resolutions adopted on 20.10.2020 in the field of EU legislation on artificial intelligence on: a framework of ethical aspects of artificial intelligence, robotics and related technologies ${ }^{119}$; a civil liability regime for artificial intelligence ${ }^{120}$ and intellectual property rights for the development of artificial intelligence technologies ${ }^{121}$. The parliamentarians agreed that, above all, AI regulations should be human-centred. The human being is put at the centre of any solution and the aim of regulation should be his or her safety ${ }^{122}$, achieved by ensuring transparency in the functioning of the algorithms, non-discriminatory operation ${ }^{123}$, as well as the right of redress against their operators, not excluding privacy and data protection issues.

Prior control is certainly not just a manifestation of current AI trends. For example, for the purposes of the eIDAS Regulation ${ }^{124}$, an obligation was established to audit the qualified services launched, covering both documentation and IT systems audit. This approach is particularly justified in view of the fact that these services are associated with a number of legal presumptions, e.g. as to the authenticity or integrity of data and service $^{125}$. However, state regulations of some countries are the most developed, and the following examples of such national regulations are the

119 <https:/www.europarl.europa.eu/doceo/document/TA-9-2020-0275_EN.html> access 16 March 2021.

$120<$ https:/www.europarl.europa.eu/doceo/document/TA-9-2020-0276_EN.html> access 16 March 2021.

$121<$ https:/www.europarl.europa.eu/doceo/document/TA-9-2020-0277_EN.html> access 16 March 2021.

122 The proposed revision of the NIS Directive deserves additional attention as regards cyber security, <https://ec.europa.eu/digital-single-market/en/news/prop osal-directive-measures-high-common-level-cybersecurity-across-union $>$ access 16 March 2021; unfortunately, the LegalTech sector is not directly mentioned in the regulation, although Annex 1 includes cloud service providers among the entities belonging to the group of "essential entities".

123 For an extensive study of the problems of algorithmic discrimination in Europe, see the special report prepared for the European Commission - Janneke Gerards and Raphaële Xenidis, 'Algorithmic discrimination in Europe: Challenges and opportunities for gender equality and non-discrimination law' (European Commission 2020) <https:/op.europa.eu/en/publication-detail/-/publication/082f1db c-821d-11eb-9ac9-01aa75ed71a1> access 16 March 2021;

124 Regulation (EU) No 910/2014 of the European Parliament and of the Council of 23 July 2014 on electronic identification and trust services for electronic transactions in the internal market and repealing Directive 1999/93/EC.

125 Dariusz Szostek, 'IBAC (IoT, Blockchain, AI i Cyberbezpieczeństwo) - samoregulacja kodów czy kontrola uprzednia?’ in Kinga. Flaga-Gieruszyńska, Jacek 
Maltese Virtual Financial Assets Act ${ }^{126}$, Malta Digital Innovation Authority Act ${ }^{127}$ i Innovative Technology Arrangement and Services Act ${ }^{128}$. Within these arrangements, an appropriate Malta Digital Innovation Authority (MDIA) ${ }^{129}$ licence is required to provide Virtual Financial Assets ${ }^{130}$ services. It is worth noting that the mentioned legal act also introduces many requirements for further control, including with respect to whitepapers of Initial VFA Offerings ${ }^{131}$, which must contain, in particular, detailed descriptions of smart contracts $^{132}$, oracles ${ }^{133}$ or intellectual property rights related to the offer ${ }^{134}$.

Gołaczyński and Dariusz Szostek (eds), Sztuczna inteligencja, blockchain, cyberbezpieczeństwo oraz dane osobowe. Zagadnienia wybrane (C. H. Beck 2019);

126 Virtual Financial Assets Act (VFA) <https://legislation.mt/eli/cap/590/eng/pdf > access 2 February 2021.

127 Malta Digital Innovation Authority Act (MDIA) <https://legislation.mt/eli/cap/5 91/eng/pdf $>$ access 2 February 2021.

128 Innovative Technology Arrangement and Services Act (ITAS) $<$ https://legislation .mt/eli/cap/592/eng/pdf $>$ access 2 February 2021.

129 Part III and IV of VFA Act.

130 For the purposes of the VFA Act, VFA means any form of digital storage that is used as a digital medium of exchange, unit of account or store of value that is not simultaneously: (1) electronic money, (2) a financial instrument or (3) a virtual token.

131 This term covers in principle Initial Coin Offering (ICO), Investopedia, 'Initial Coin Offering' < https://www.investopedia.com/terms/i/initial-coin-offering-ico.a sp> access 2 February 2021.

132 Including, but not limited to, adopted standards, core protocols, functionalities and associated operating costs, as well as any built-in constraints, if any, including investment and geographical.

133 Entities offering services of obtaining and verifying data described in smart contracts; see also Patrick Collins, 'What Is a Blockchain Oracle?' (Medium, 2 September 2020) <https://medium.com/better-programming/what-is-a-blockch ain-oracle-f5ccab8dbd72> accessed 10 February 2021. Taking this opportunity, it is worth pointing out in this regard that the tendency to view the crypto-asset market as inherently independent seems to be completely unfounded, since, as in AI systems, the correctness of the operation of smart contracts depends on the quality of the data provided, which are in the possession of the aforementioned oracles. As a result, smart contracts are in principle entirely dependent on the providers of such services, which means that the postulate of no specific control is not applicable in practice.

134 Detailed regulations in this respect are contained in the First Schedule to VFA Act. 


\subsection{Follow-up actions}

The control of algorithms is also directly affected by follow-up actions, including, in particular, the attribution of liability for AI. The European Parliament proposes a solution that will apply to physical and virtual AI activities that will cause material damage or serious non-material damage resulting in verifiable economic loss. Liability rules are differentiated according to the classification of AI technology as high-risk ${ }^{135}$. Operators of AI systems that fall into this category should also be subject to compulsory third party liability insurance similar to that for drivers of passenger vehicles $^{136}$. However, it should be noted that the proposed solutions concern only artificial intelligence systems, so to the extent to which individual codes do not meet the conditions contained in the final regulation, liability for them will be shaped differently ${ }^{137}$.

In terms of the development of smart contracts and their control, the most interesting trend is the implementation of dispute resolution mechanisms and protocols (following N. Szabo's terminology that a smart contract is a combination of protocols), of which Aragon Court (trade name, see Figure 5) is a working example. This program can be qualified as ADR in an adjunctive model but as a private initiative, i.e. aimed at resolving disputes which have arisen from smart contracts related to Aragon Network token transactions (ANT) ${ }^{138}$. There are also first statements and opinions expressed in the international doctrine that the development of dispute resolution protocols for smart contracts is also a signal for changes in traditional courts and arbitration ${ }^{139}$.

135 Paragraphs 14-22 of the European Parliament resolution of 20.10.2020 with recommendations to the Commission on a civil liability regime for artificial intelligence [2020/2014(INL)].

136 ibid, paragraphs 23-25.

137 European Parliament proposes definition of "artificial intelligence system" as "system that is either software-based or embedded in hardware devices, and that displays intelligent behaviour by, inter alia, collecting, processing, analysing, and interpreting its environment, and by taking action, with some degree of autonomy, to achieve specific goals".

138 World Economic Forum, 'Bridging the Governance Gap: Dispute resolution for blockchain-based transactions' (White Paper, December 2020) access 16 March 2021.

139 Bedrettin Gürcan, 'Jurisdiction on Blockchain' (2020) ICBEMM-ICISSS 14. 
Figure 5. The types of disputes possible for parties to smart contracts and the mechanisms and protocols for resolving them. The figure indicates the location of the Aragon Court dispute resolution protocol along with the type of disputes it allows to be resolved

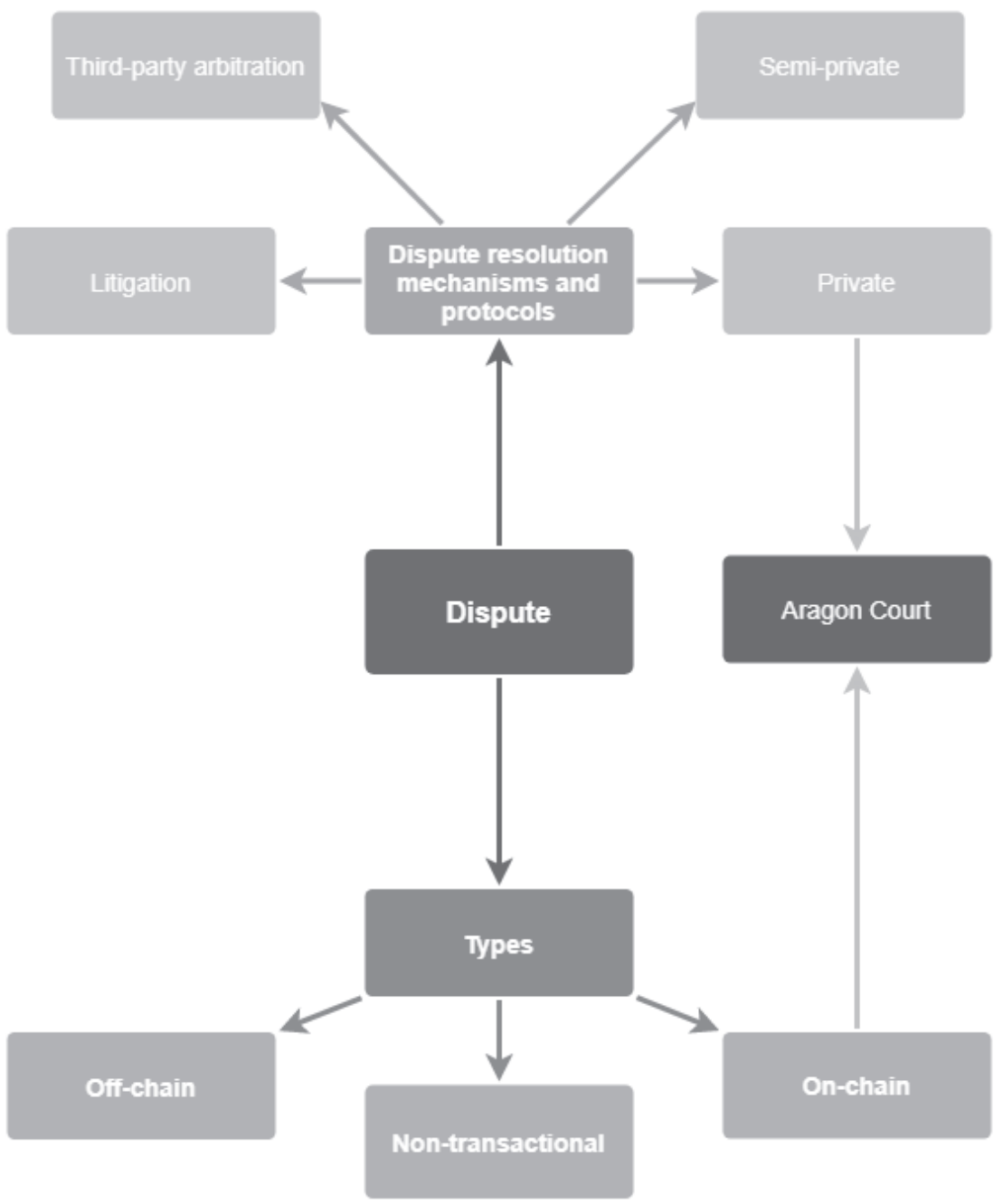

Source: Own elaboration based on World Economic Forum, Bridging the Governance Gap: Dispute resolution for blockchain-based transactions, 2020, https://ww w.weforum.org/whitepapers/bridging-the-governance-gap-dispute-resolution-for-bl ockchain-based-transactions. 
Private dispute resolution mechanisms and protocols are not an issue that characterises the codes in DLT. Aragon Court or Kleros ${ }^{140}$ provides human participation in their operation at a reasonably advanced degree. The parties, i.e. humans, mark their objections to the transaction with evidence and also humans vote on the verdict (the verdict works on the principle: either side A or B is right). While the algorithm uses the laws of mathematics and programming code, the operation of the code is initiated by a human (a party to the dispute) and the decision is made by people, although it is also verified on the basis of game theory, i.e. the party that gets more votes wins the dispute. Codes on social platforms are not as transparent in their operation as private adjudication models ${ }^{141}$. In these, it is not easy to establish the role and involvement of the human in controlling the operation of the code $(\mathrm{ADM})$. Furthermore, the basis of the decision is unknown ${ }^{142}$.

\subsection{Soft Law}

In the context of scrutiny, there is also a need to mention standards that aim to help, i.e. to indicate certain good practices. This is important to signal because EP Resolution 2020/2012 (INL), which appears in the context of artificial intelligence, robotics and related technologies, indicates that future EU law will focus on such a target as code developers, whose choices regarding development, deployment and use will determine not only the benefits but also the impact of codes on society (see Figure 6). This approach led EP Resolution 2020/2012 (INL) to point out in paragraph 11 that $"(. .$.$) the development, deployment and use of artificial intelligence,$

140 Kleros is similar project to Aragon Court, <kleros.io/> accessed 12 January 2021.

141 Mark R. Leiser, 'Private jurisprudence' and the right to be forgotten balancing test' (2020) 29 Computer Law \& Security Review; See Przemysław Polański, 'Zwalczanie bezprawnych treści oraz zapewnienie retrievedności cyfrowej z pomocą algorytmów sztucznej inteligencji' in Luigi Lai and Marek Świerczyński (ed) Prawo sztucznej inteligencji (C. H. Beck 2020).

142 However, it is worth noting here the proposed regulation of the European Parliament and of the Council on a Single Market For Digital Services (Digital Services Act) and amending Directive 2000/31/EC [COM(2020) 825 final], which provides for a number of control mechanisms for online platforms, including those based on internal complaint handling systems (Article 17), out-of-court dispute resolution (Article 18) and instruments of enhanced supervision of very large online platforms (Article 50 et seq.). Also noteworthy is the need for very large online platforms to designate dedicated compliance officers (Article 32). 
robotics and related high-risk technologies, including but not limited to human handling, shall always be ethically guided, and designed to respect and allow for human agency and democratic oversight, as well as allow the retrieval of human control when needed by implementing appropriate control measures". The term "democratic oversight" seems to refer to oversight arising from the specificity of the relationship between European law and technical standards, the preparation and dissemination of which are handled by standardisation organisations. They will also be expected to provide a framework of good practice for code developers. Compliance with technical standards will be ensured by the developers themselves. They will have to submit to certification by audit checks when required by law or when they consider it a necessary business action. A properly conducted audit will confirm implementation and operation according to good practice. This type of action is also in line with the technological neutrality of European regulations - it is the technical standards that will indicate current and essential directions for developers' solutions. This also supports the concept of self-regulation and use of DLTs proposed by D. Szostek. Another element of democratic oversight may be an administrative body that will license creators ${ }^{143}$. Such democratic oversight represents, on the one hand, specific benefits for European society and, on the other hand, the certainty that the impact of creators and their codes on fundamental rights and social and economic principles and values will not remain outside oversight and control. In this way, the potential for opportunity creation can be achieved (Figure 6).

143 In the context of licensing, see also European Commission Communication Open Source Software: European Commission, 'OPEN SOURCE SOFTWARE STRATEGY 2020 - 2023 Think Open' (Communication to the Commission, 21 November 2020) <https://ec.europa.eu/info/sites/default/files/en_ec_open_source _strategy_2020-2023.pdf > accessed 12 January 2021. 
Figure 6. Graphical representation of the significant element of control in terms of EP Resolution 2020/2012 (INL) and justification

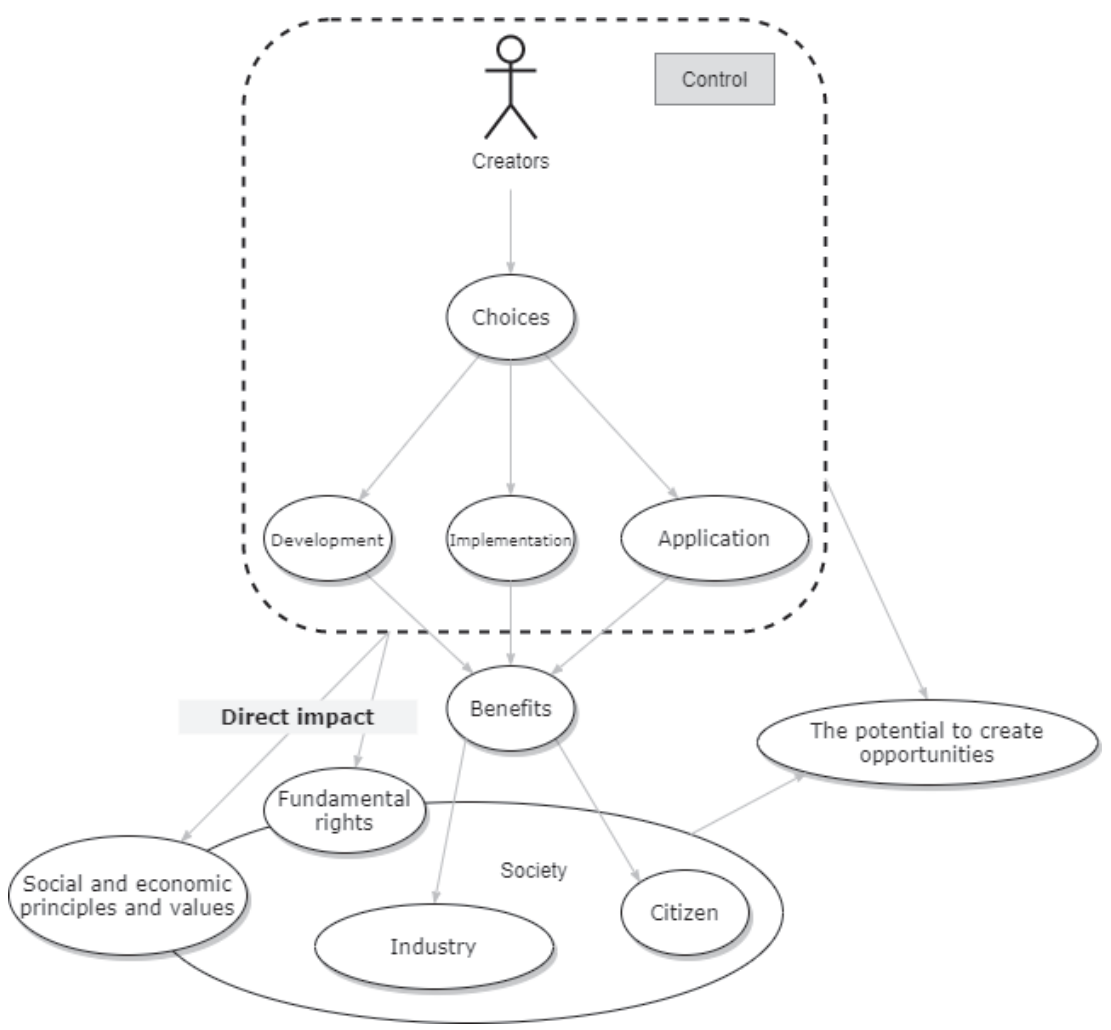

Source: Own elaboration.

\section{Summary}

In terms of comparing smart contract codes with AI codes, it is essential to note that both codes implement ADM but differently. An automated decision realised by deep learning can be complex, not very transparent, and depends on the inputs on which such AI has trained. On the other hand, smart contracts offer code in a trackable form for a person with knowledge of a particular contractual programming language as well as they also by assumption offer easy accessibility to this code, and thus high transparency. Besides, their aim is not to eliminate but to reduce the 
human factor, mainly the one who stands in the intermediary place and is not a party.

Furthermore, there is no legislation that directly addresses codes in a universal manner. What is regulated are entities that use codes to create programs or by using programs themselves, fall within a certain regulatory framework. However, it seems that the European Union has started to notice the problem of increased control of entities operating in cyberspace, which is confirmed by the work on regulations dedicated to digital services $^{144}$ and markets ${ }^{145}$. The control solutions drafted for the purpose of the mentioned acts should be considered important to observe and worth considering also in the broader context indicated in this work. Unfortunately, a drawback of the proposed provisions is that their scope is still limited to basic platform services offered by access gatekeepers ${ }^{146}$ or "to certain specific categories of intermediary service providers"147. The lack of adequate general regulations raises many doubts, even with regard to the legal status of the codes themselves.

We must bear in mind that the success of tokens depends on their legal recognition so that they can be effective in the real world and, thus, on their compliance with applicable law. If not, cryptocurrencies will bring us none "technical revolution"148. Will we live to see the "lex cryptographia"149, a branch of law regulating tokens and their turnover? We are now witnessing the process of creating such a law. In the last few years, we have been flooded with token regulations, especially in countries or territories with high digital competences, PRC, US and the EU among them. In total, these cover over 2 billion entities. And this is no longer a trivial group. For lawyers the tomorrow has started today or, maybe, it started yesterday but no one noticed?

There is therefore no doubt that efforts need to be made to begin work on the issues identified. It is important, however, to approach the

144 Proposal for a Regulation of the European Parliament and of the Council on a Single Market For Digital Services (Digital Services Act) and amending Directive 2000/31/EC, $\operatorname{COM(2020)~} 825$ final.

145 Proposal for a Regulation of the European Parliament and of the Council on contestable and fair markets in the digital sector (Digital Markets Act), $\operatorname{COM}(2020) 842$ final.

146 See Article 1(2) of the draft Digital Markets Act.

147 See Article 1(1)(b) of the draft Digital Services Act.

148 See: as to one of the first uses of the term: Don Tapscott and Alex Tapscott, Blockchain revolution. How The Technology Behind Bitcoin Is Changing Money, Business, And The World (Penguin Random House 2016).

149 See: Wright and De Filippi (n 4) 48-56. 
control mechanisms carefully so as not to create a situation of overregulation of the market. Excessive legal restrictions may effectively block the development of new technologies and progress because of the high entry threshold for compliance with the standards in force. As a result, instead of ensuring security and transparency, mechanisms of control will become a monopolising instrument, as only technological giants will be able to afford to operate in such areas.

It should also be noted that algorithmisation appears not only on the ground of law from the perspective of legal practice but also from the impact of law on society. However, these are issues that fall under the broad term of cybernetics and the relationship of the citizen to the state apparatus. Although this apparatus also includes bodies both applying the law and overseeing compliance with the law, it is more about the algorithms that allow and regulate access to these bodies and allow the state to carry out its functions ${ }^{150}$.

150 See Thomas D. Grant and Damon Wischik, On the path to AI. Law's prophecies and the conceptual foundations of the machine learning age (Palgrave Macmillan 2020). See Tom Barraclough, Hamish Fraser and Curtis Barnes, 'Legislation as a code for New Zeland: opportunities, risks, and recomendations' (2021) 3 NZLFRRp 12-13. 
